\title{
Fed-Batch Feeding Strategies for Enzymatic Biodiesel Production
}

\section{Price, Jason Anthony; Nordblad, Mathias; Woodley, John; Huusom, Jakob Kjøbsted}

Published in:

Preprints of the 19th World Congress The International Federation of Automatic Control.

Publication date:

2014

Link back to DTU Orbit

Citation (APA):

Price, J. A., Nordblad, M., Woodley, J., \& Huusom, J. K. (2014). Fed-Batch Feeding Strategies for Enzymatic Biodiesel Production. In Preprints of the 19th World Congress The International Federation of Automatic Control. (pp. 6204-6209)

\section{General rights}

Copyright and moral rights for the publications made accessible in the public portal are retained by the authors and/or other copyright owners and it is a condition of accessing publications that users recognise and abide by the legal requirements associated with these rights.

- Users may download and print one copy of any publication from the public portal for the purpose of private study or research.

- You may not further distribute the material or use it for any profit-making activity or commercial gain

- You may freely distribute the URL identifying the publication in the public portal

If you believe that this document breaches copyright please contact us providing details, and we will remove access to the work immediately and investigate your claim. 


\title{
Fed-Batch Feeding Strategies for Enzymatic Biodiesel Production
}

\author{
Jas on Price*, Mathias Nordblad*, John M. Woodley*, Jakob K. Huusom** \\ *Center for Process Engineering and Technology, Department of Chemical and Biochemical Engineering, Technical \\ University of Denmark, Building 229, DK-2800 Kgs. Lyngby, Denmark (e-mail: [japr,matn,jw]@ kt.dtu.dk). \\ **CAPEC, Department of Chemical and Biochemical Engineering, Technical University of Denmark, Søltofts Plads, Building \\ 229, DK-2800 Kgs. Lyngby, Denmark (e-mail: jkh@kt.dtu.dk)
}

\begin{abstract}
In this work a kinetic model for the enzymatic transesterification of rapeseed oil using a solubilised lipase (Callera Trans L-Thermomyces lanuginosus) was developed from first principles. The model is based on a Ping-Pong Bi-Bi mechanism, with methanol inhibition, along with consideration of the differences in the interfacial and bulk concentrations of the enzyme. The model is then used to evaluate various feeding strategies to improve the enzymatic biodiesel production. The feeding strategies investigated, gave insight into how the methanol should be fed to potentially mitigate enzyme deactivation while improving the biodiesel yield. The best experimental results gave a yield of $703.76 \mathrm{~g}$

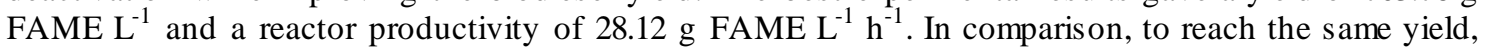
the optimised two step feeding strategy took 6.25 hours less, which equates to an increase the reactor productivity of $36.9 \%$.
\end{abstract}

Keywords: Modelling, Sensitivity Analysis, Monte-Carlo Simulations, Enzymatic Biodiesel

\section{INTRODUCTION}

Compared to the conventional alkali-catalysed biodiesel process, the enzymatic process is considered a "green reaction". It requires less energy and is also highly selective producing a very high purity product with less downstream operations (Xu et al. 2011, Akoh et al. 2007, Nielsen et al. 2008). If the biocatalyst is to be reused, one challenge is mitigating the effects of inhibition and deactivation of the enzyme by the methanol substrate. To overcome the effects due to the methanol, researchers employ a stepwise feeding of methanol to the reactor (Samukawa et al. 2000, Lv et al. 2010, Du et al. 2005). However the methods that are employed are far from optimal. In order to optimize the enzymatic biodiesel process, numerous experiments are done to help characterize the system. Modelling can be a valuable tool to help focus the experimental work needed for process understanding and to support further process development. Integral to the modelling of the biodiesel process from first principles, is the availability of reliable kinetic models.

Descriptions of the various kinetic models for enzymatic transesterification of vegetable oils are quite numerous (AlZuhair 2005, Pilarek and Szewczyk 2007, Cheirsilp et al. 2008, Calabrò et al. 2010, Li et al. 2010, Lv et al. 2010, Fedosov et al. 2012). In terms of determining the optimal methanol feeding profile, the current kinetic models in literature are not able to predict the concentration of the major species over the entire course of the reaction, for changes in the process conditions such as:
1. Alcohol/oil molar ratio
2. Water and Free fatty acid concentrations
3. Different enzyme loadings
4. Interfacial area of the oil-water interface

The aim of this work is to:

- Develop a mechanistic model from first principles that takes into consideration the effects of the process conditions outlined.

- Use the proposed model to evaluate various feeding strategies to improve the biodiesel production while constraining the maximum allowable concentration of methanol in the reactor.

The article is organised as follows. The model formulation is presented, along with the two feeding strategies. The results of the parameter estimation are discussed along with the results of the feeding strategies. The uncertainty in one of the feeding strategies due to the uncertainty in the parameter estimates is then investigated.

\section{MODEL FORMULATION AND METHODS}

\subsection{Model formulation}

The mathematical model describing the transesterification reaction in the biphasic oil-water system with a soluble lipase (Callera Trans L-Thermomyces lanuginosus) was formulated on the basis of the following assumptions:

1. The reaction proceeds via a Ping-Pong Bi-Bi mechanism

2. No inhibition by the substrate

3. Competitive alcohol inhibition

4. The interfacial and bulk concentrations of the substrate and products are the same (mass transfer from the bulk to the interface is instantaneous)

5. Acyl migration can be ignored

6. All reaction steps are reversible 
By including the interfacial enzyme concentration $(E)$, the reaction scheme then proceeds as shown in Table 1.

The total specific interfacial area of a droplet $\left(a_{T}\left[\mathrm{~m}^{2} / \mathrm{m}^{3}\right]\right)$ can be represented as:

$$
a_{T}=\frac{6}{d_{s}} \cdot \frac{V_{p}}{V}
$$

Where $d_{s}$ is the Sauter mean diameter of the droplets in the system - $5.88 \times 10^{-6}[\mathrm{~m}], V_{p}$ is the size of the polar volume $\left[\mathrm{m}^{3}\right]$ and $V$ is the bulk volume $\left[\mathrm{m}^{3}\right]$.

Given the enzyme coverage $A_{e}\left[\mathrm{~m}^{2} / \mathrm{mole}\right]$, it is possible to calculate the free specific interfacial area, $a_{f}\left[\mathrm{~m}^{2} / \mathrm{m}^{3}\right]$ as seen in (2). Note, it is assumed the size of the various enzyme substrate complexes don't vary significantly from the size of the free enzyme (Jurado et al. 2008).

$$
a_{f}=a_{T}-A_{e} \cdot(E+E X+E T+E D+E M+E C H)
$$

The free specific interfacial area can then be expressed as a concentration $\left(A_{f}\left[\mathrm{~mol} / \mathrm{m}^{3}\right]\right)$ by using the enzyme coverage to estimate a theoretical upper limit of the moles of enzyme molecules that can occupy the interface.

$$
A_{f}=a_{f} / A_{e}
$$

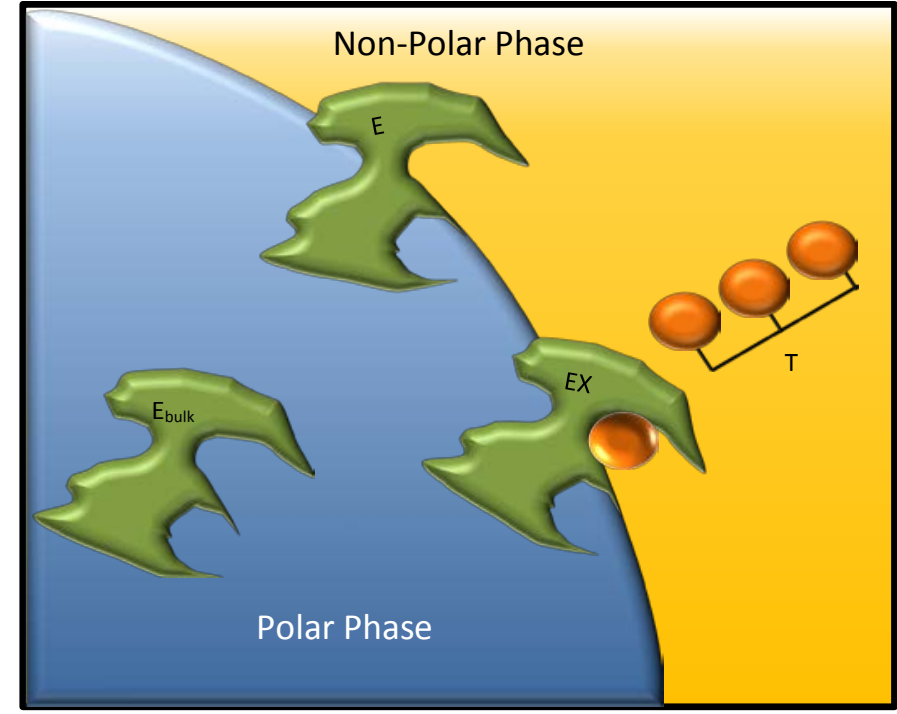

Fig. 1. Diagrammatic representation of the enzyme at the oil water interface. The polar phase contains water, methanol, glycerol and the Free enzyme $\left(E_{\text {bulk }}\right)$. The nonPolar phase contains the oil components along with the biodiesel formed. At the interface is the penetrated enzyme

\begin{tabular}{|c|c|c|c|c|}
\hline i & \multicolumn{2}{|c|}{ Reactions } & Rate of reaction $\left(r_{i}\right)$ & Differential mass balance Eqns. for Fed-Batch \\
\hline 1 & $E_{\text {bulk }}+A_{f} \leftrightarrow E$ & $\begin{array}{l}\text { Enzyme in bulk absorbed at the } \\
\text { interface }\end{array}$ & $k_{1} \cdot\left[E_{\text {butk }}\right] \cdot\left[A_{f}\right]-k_{-1} \cdot[E]$ & $d([T] \cdot V) / d t=-V\left(r_{2}\right)$ \\
\hline 2 & $T+E \leftrightarrow E . T$ & \multirow{6}{*}{$\begin{array}{l}\text { In reactions } 2,4 \text { and } 6 \text { the } \\
\text { penetrated enzyme can react } \\
\text { with the substrate to form an } \\
\text { enzyme substrate complex E.T, } \\
E . D \text { or } E . M \text { (Ping) }\end{array}$} & $k_{2} \cdot[T] \cdot[E]-k_{-2} \cdot[E T]$ & $d([D] \cdot V) / d t=V\left(r_{3}-r_{4}\right)$ \\
\hline 3 & $E . T \leftrightarrow E X+D$ & & $k_{3} \cdot[E T]-k_{-3} \cdot[E X] \cdot[D]$ & $d([M] \cdot V) / d t=V\left(r_{5}-r_{6}\right)$ \\
\hline 4 & $D+E \leftrightarrow E . D$ & & $k_{4} \cdot[D] \cdot[E]-k_{-4} \cdot[E D]$ & $d([B D] \cdot V) / d t=V\left(r_{9}\right)$ \\
\hline 5 & $E . D \leftrightarrow E X+M$ & & $k_{5} \cdot[E D]-k_{-5} \cdot[E X] \cdot[M]$ & $d([F A] \cdot V) / d t=V\left(r_{8}\right)$ \\
\hline 6 & $M+E \leftrightarrow E . M$ & & $k_{6} \cdot[M] \cdot[E]-k_{-6} \cdot[E M]$ & $d([G] \cdot V) / d t=V\left(r_{7}\right)$ \\
\hline 7 & $E . M \leftrightarrow E X+G$ & & $k_{r} \cdot[E M]-k_{-7} \cdot[E X] \cdot[G]$ & $d([W] \cdot V) / d t=-V\left(r_{8}\right)$ \\
\hline 8 & $E X+W \leftrightarrow F F A+E$ & \multirow{2}{*}{$\begin{array}{l}\text { The acyl enzyme complex can } \\
\text { then react with water or } \\
\text { methanol (Pong) and then } \\
\text { release the second product } F A \\
\text { or } B D \text { (Ping) }\end{array}$} & $k_{s} \cdot[E X] \cdot[W]-k_{-s} \cdot[F F A] \cdot[E]$ & $d([\mathrm{CH}] \cdot V) / d t=-V\left(r_{9}+r_{10}\right)$ \\
\hline 9 & $E X+C H \leftrightarrow B D+E$ & & $k_{g} \cdot[E X] \cdot[C H]-k_{-9} \cdot[B D] \cdot[E]$ & $d([E] \cdot V) / d t=V\left(r_{1}+r_{8}+r_{9}-r_{2}-r_{4}-r_{6}-r_{10}\right)$ \\
\hline 10 & $C H+E \leftrightarrow E . C H$ & $\begin{array}{l}\text { Reversible competitive } \\
\text { methanol inhibition }\end{array}$ & $k_{10} \cdot[C H] \cdot[E]-k_{-10} \cdot[E C H]$ & $d([E X] \cdot V) / d t=V\left(r_{3}+r_{5}+r_{7}-r_{8}-r_{9}\right)$ \\
\hline \multirow{7}{*}{\multicolumn{4}{|c|}{$\begin{array}{l}\text { Note: } \\
\text { 1. T, } D, M, G, C H, B D, W, F F A, A_{f}, E_{b u l k}, E, E X, F_{a}, R_{G} \text {, and } R_{W} \text { are } \\
\text { Triglyceride, Diglyceride, Monoglyceride, Glycerol, Alcohol, Biodiesel, } \\
\text { Water, Free fatty acid, Free Interfacial area, Free enzyme bulk } \\
\text { concentration, Penetrated enzyme, acyl enzyme complex, volumetric flow } \\
\text { fate of methanol and the volumetric net rates of production of Glycerol and } \\
\text { Water respectively. E.T represents the Enzyme Triglyceride complex } \\
\text { formed and extends to the other complexes formed. Units for the } \\
\text { concentrations are in mol/ } \mathrm{m}^{3} \text {. } \\
\text { 2. Intermediate steps for reactions } 2 \text { - } 9 \text { were grouped together given } \\
\text { interest is in the overall rate } \\
\text { 3. The differential equation to estimate the polar volume neglects the } \\
\text { change in density of the system. }\end{array}$}} & $d([E . T] \cdot V) / d t=V\left(r_{2}-r_{3}\right)$ \\
\hline & & & & $d([E . D] \cdot V) / d t=V\left(r_{5}-r_{6}\right)$ \\
\hline & & & & $d([E . M] \cdot V) / d t=V\left(r_{6}-r_{7}\right)$ \\
\hline & & & & $d([E . C H] \cdot V) / d t=V\left(r_{10}\right)$ \\
\hline & & & & $d\left(\left[E_{b u l k}\right] \cdot V\right) / d t=-V\left(r_{1}\right)$ \\
\hline & & & & $d(V) / d t=\left(F_{a}\right)$ \\
\hline & & & & $d\left(V_{p}\right) / d t \quad=R_{G}+R_{w}$ \\
\hline
\end{tabular}
(E) and the Acyl Enzyme complex (EX)

Table 1. Rate and differential mass balance equations for a feed batch reactor 
The mass balance for the system is then combined with the kinetics to give the system of ordinary differential equations presented in Table 1. An illustration of the enzyme and its complexes is presented in Fig. 1.

\subsection{Parameter Estimation}

The 20 unknown kinetic constants $\left(k_{1}-k_{10}, k_{-1}-k_{-10}\right)$ were estimated by fitting the model equations with six sets of experimental data and a seventh validation data set is used to judge the quality of the fitting. The experiments considered can be seen in Table 2 .

The parameter estimation was performed in Matlab. The differential equations are solved using a stiff variable order solver based on the numerical differentiation formulas (ode15s). The parameter fitting minimizing the squared-sum of the relative errors between the simulated and experimental values for $T, D, M, B D$ and FFA using fminsearch which is based on a simplex search algorithm (Jeffrey C. Lagarias 1998).

\subsection{Methanol Feeding Optimization}

Given that the transesterification reaction is reversible, an excess of methanol is needed to push the reaction to its equilibrium conversion. For this enzyme formulation, at least 1.5 molar equivalents (Eq.) of methanol are necessary (1 Eq. of methanol corresponds to the ratio of 3 moles of methanol to 1 mole of triglyceride). However, high concentrations of methanol will cause the activity of the enzyme to decrease due to methanol inhibition and irreversibly deactivate the enzyme (Al-Zuhair et al. 2007). The mechanism for methanol inhibition is covered in the model presented, however deactivation of the enzyme is not, due to insufficient experimental data to characterise the phenomena. Samukawa and co-workers found that they can increase the reuse of the immobilised enzyme (a clear indication of a reduction in enzyme deactivation), by using a stepwise feeding strategy. This kept the methanol content in the reactor below the concentration that gave the highest initial rate of FAME production (Samukawa et al. 2000). Hence we wished to

Table 2. Experiments used for the data fitting

\begin{tabular}{|c|c|c|c|}
\hline Exp.* & $\begin{array}{c}\text { Enzyme } \\
{[\mathrm{wt} . \% \text { oil ] }}\end{array}$ & $\begin{array}{c}\text { Water } \\
{[\text { wt.\% oil ] }}\end{array}$ & $\begin{array}{c}\text { Methanol Feed rate } \\
{[\mathrm{Eq} . / \mathrm{h}]}\end{array}$ \\
\hline 1 & 0.1 & 3 & 0.06 \\
\hline 2 & 0.2 & 3 & 0.06 \\
\hline 3 & 0.3 & 3 & 0.06 \\
\hline 4 & 0.2 & 5 & 0.06 \\
\hline 5 & 0.5 & 5 & 0.06 \\
\hline 6 & 0.3 & 5 & 0.1 \\
\hline 7 & 0.5 & 5 & $\begin{array}{c}0.185 \text { first 2hrs. } 0.06 \\
\text { thereafter }\end{array}$ \\
\hline \multicolumn{4}{|c|}{$\begin{array}{l}* \text { Experiment settings: } 1.5 \text { Equivalents of } \mathrm{CH} \text { is reacted with } \\
110 \mathrm{~g} \text { of Rapeseed oil }(1 \mathrm{Eq} \text {. is } 1 \mathrm{~mol} \text { oil : } 3 \mathrm{~mol} \mathrm{CH}) \text {. The } \\
\text { reaction takes place in a } 0.25 \mathrm{~L} \text { reactor at } 35^{\circ} \mathrm{C} \text { with mixing by a } \\
\text { rushton turbine, spinning at } 1400 \mathrm{rpm} \text {. Initial Methanol dosed is } \\
0.2 \mathrm{Eq} \text {. }\end{array}$} \\
\hline
\end{tabular}

extend their work by actually being able to maintain the concentration of methanol in the reactor $\left(\left\{\mathrm{CH}_{\text {critical }}\right\}\right)$ that gave the best initial rate, at each time increment $t_{i}$, by minimizing the objective function in (4).

$$
\min J_{E q}=\left(\left\{\mathrm{CH}_{E q}\right\}_{t_{i}}-\left\{C H_{\text {critical }}\right\}_{t_{i}}\right)^{2}
$$

The control vector for the methanol feed rate is, $F=$ $\left[F_{1}, F_{2} \ldots F_{N}\right]^{T},[\mathrm{~L} / \mathrm{min}]$ and the same experimental settings in Exp. 1-7 are used along with the simulation settings in Table 3 to investigate the effects how the lower number of feed increments (Opt.1, N=2) and upper number of feed increments (Opt.2, $\mathrm{N}=20$ ) affects the process.

The objective function in (5) is used to find the initial amount of methanol dosed, that achieves the highest initial rate of FAME production $\left(I R_{F A M E}\right)$. A value of $0.525 \mathrm{Eq}$. is found, and is used in the rest of the simulations.

$$
\underset{C H_{0}}{\max J_{I R}}=I R_{\text {FAME }}
$$

\subsection{Uncertainty analysis}

As in our previous work (Price et al. 2013), the Monte Carlo method was used to propagate the uncertainty of the kinetic parameters on the output (prediction) uncertainty of the model (Sin et al. 2009). The confidence intervals from the parameter fitting is used to specify the input uncertainty in the parameter estimates and Latin hypercube sampling with correlation control is used for sampling of the parameters in the sample parameter space (Helton and Davis 2003).

\section{RESULTS AND DISCUSSION}

\subsection{Parameter Estimates and model validation}

The histogram of the residuals (Fig. 2), for the fitting of Exp. 1-6 is used to assess the quality of the model fitting. With a mean of -0.07 mass \% and standard deviation of 2.62 mass $\%$, this signifies that $95 \%$ of the residuals lie within $-0.07 \pm 5.24$ mass \%. Given a mass balance on the acyl groups close to within 3 mass \%, this means that the proposed model explains the experimental data quite well.

The parameter estimates are shown in Table 4 along with the confidence intervals obtained. Generally, the narrower the confidence interval, the higher the quality of the parameter estimate. Fig. 3 shows the performance of the parameter estimates on the validation data set (Exp.7). For the

Table 3. Simulation settings for the Feeding strategy

\begin{tabular}{|l|c|c|}
\hline \multirow{2}{*}{ Settings } & \multicolumn{2}{|c|}{ Strategy 1 } \\
\cline { 2 - 3 } & Opt.1 & Opt.2 \\
\hline CH $_{\text {critical }}$ [Eq.] & 0.525 & 0.525 \\
\hline $\boldsymbol{C H}_{@ \text { t=0 }}$ [Eq.] & 0.525 & 0.525 \\
\hline Enzyme [wt.\% oil ] & 0.5 & 0.5 \\
\hline Water [wt.\% oil ] & 5 & 5 \\
\hline $\mathbf{N}$ - number of feed increments & 2 & 20 \\
\hline $\boldsymbol{t}_{\text {end }}$ [min] & 1500 & 1500 \\
\hline
\end{tabular}




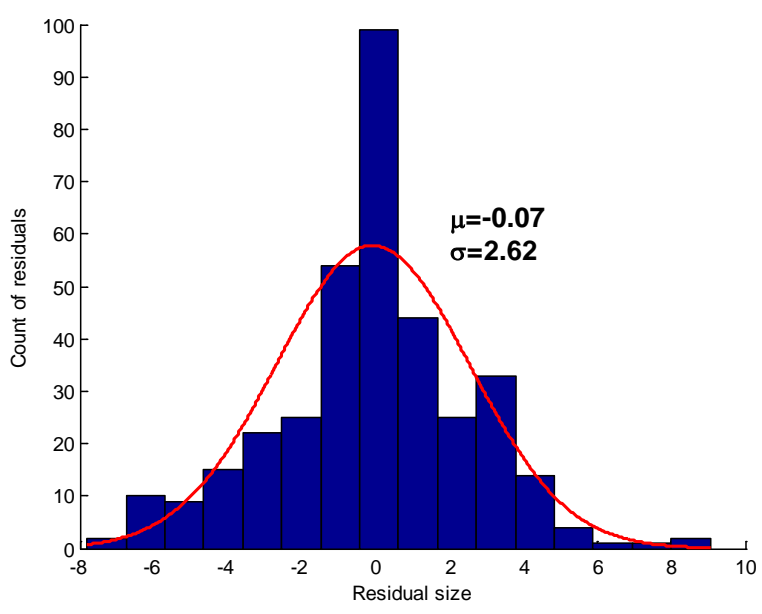

Fig. 2 Histogram of residuals for the fitting of Exp. 1-6. The distribution has a mean of $-\mathbf{0 . 0 7}$ mass $\%$ and a standard deviation of 2.62 mass \%

validation data set, a different methanol feeding scenario is used. Initially the methanol feeding is high $(0.185 \mathrm{Eq} . / \mathrm{h})$ in the first 2 hrs. of the reaction after which it is decreased to $0.06 \mathrm{Eq} . / \mathrm{h}$. The model captures the dynamics for the five components quite well, however the prediction for the FFA and the MAG show some deviation from the experimental data. The model mismatch observed may be due to the process phenomena not taken into consideration as well as the uncertainty in the parameter estimates. How the uncertainty in the parameter estimates affects the model outputs can be quantified via Monte-Carlo simulations. The uncertainty of the parameters is investigated later on one of the feeding strategies.

Table 4. Parameter estimates and confidence intervals

\begin{tabular}{|c|c|c|}
\hline Parameter & Mean Estimate & $\begin{array}{c}\text { Confidence } \\
\text { Interval }[ \pm \%]\end{array}$ \\
\hline $\begin{array}{ll}k_{1} & {[\mathrm{~L} / \mathrm{mol} . s]} \\
\end{array}$ & $2.07 \mathrm{E}+05$ & 4.4 \\
\hline$k_{-1}[1 / s]$ & $3.89 \mathrm{E}+04$ & 9.0 \\
\hline$k_{2}[\mathrm{~L} / \mathrm{mol} . \mathrm{s}]$ & $1.32 \mathrm{E}+05$ & 4.7 \\
\hline$k_{-2}[1 / s]$ & $8.10 \mathrm{E}+04$ & 5.0 \\
\hline$k_{3}[1 / s]$ & $1.66 \mathrm{E}+05$ & 0.8 \\
\hline$k_{-3}[\mathrm{~L} / \mathrm{mol} . s]$ & $5.76 \mathrm{E}+04$ & 7.3 \\
\hline$k_{4}[\mathrm{~L} / \mathrm{mol} . \mathrm{s}]$ & $6.46 \mathrm{E}+04$ & 2.7 \\
\hline$k_{-4}[1 / s]$ & $1.53 \mathrm{E}+05$ & 7.6 \\
\hline$k_{5}[1 / s]$ & $2.38 \mathrm{E}+04$ & 3.1 \\
\hline$k_{-5}[\mathrm{~L} / \mathrm{mol} . s]$ & $9.92 \mathrm{E}+03$ & 7.6 \\
\hline$k_{6}[\mathrm{~L} / \mathrm{mol} . \mathrm{s}]$ & $2.15 \mathrm{E}+04$ & 5.4 \\
\hline$k_{-6}[1 / s]$ & $1.56 \mathrm{E}+05$ & 4.4 \\
\hline$k_{7}[\mathrm{~L} / \mathrm{mol} . \mathrm{s}]$ & $3.76 \mathrm{E}+04$ & 7.6 \\
\hline$k_{-7}[\mathrm{~L} / \mathrm{mol} . s]$ & $1.43 \mathrm{E}+04$ & 11.3 \\
\hline $\begin{array}{ll}k_{8} & {[\mathrm{~L} / \mathrm{mol} . \mathrm{s}]}\end{array}$ & $3.36 \mathrm{E}+04$ & 5.4 \\
\hline$k_{-8}[\mathrm{~L} / \mathrm{mol} . s]$ & $8.58 \mathrm{E}+03$ & 6.5 \\
\hline$k_{9} \quad[\mathrm{~L} / \mathrm{mol} . \mathrm{s}]$ & $4.00 \mathrm{E}+04$ & 13.6 \\
\hline$k_{-9}[\mathrm{~L} / \mathrm{mol} . s]$ & $7.93 \mathrm{E}+03$ & 6.7 \\
\hline$k_{10}[\mathrm{~L} / \mathrm{mol} . \mathrm{s}]$ & $1.42 \mathrm{E}+05$ & 22.9 \\
\hline$k_{-10}[1 / \mathrm{s}]$ & $1.77 \mathrm{E}+00$ & 11.5 \\
\hline
\end{tabular}
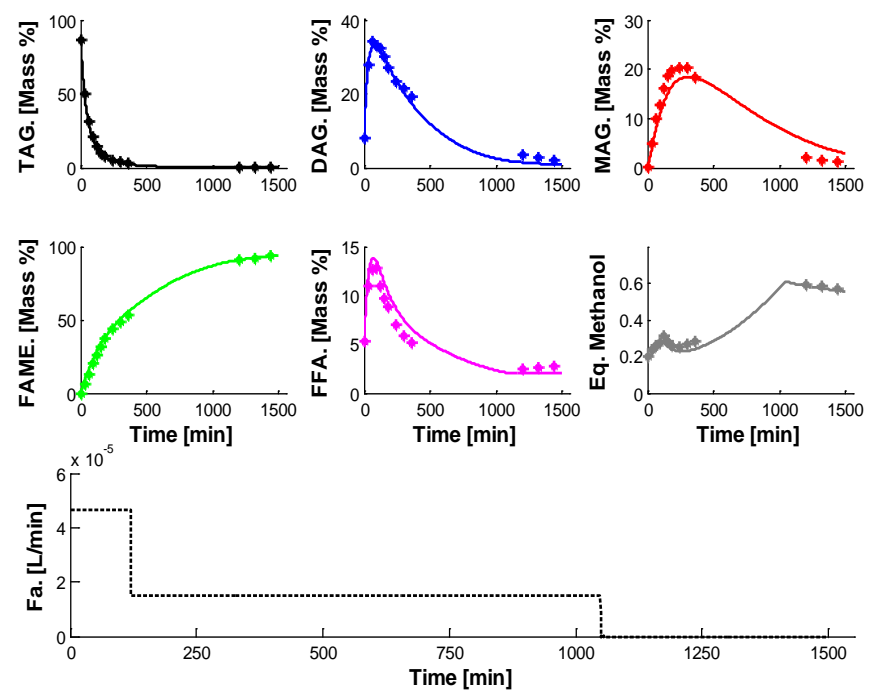

Fig. 3 Results for validation data set. Squared-sum value of $150.4[\text { Mass \% }]^{2}$

\subsection{Feeding Strategy Simulations}

The two feeding strategies simulated (Opt.1 and Opt.2), are able to satisfy the objective function in (4) at each time increment for $N=2$ and $N=20$. One possible measure to ascertain which feeding strategy is better, is to use the FAME yield. For the two feeding strategies simulated, it was possible to increase the FAME concentration throughout the entire course of the reaction as seen in the parity plot in Fig. 4. Exp.7 had the highest FAME yield $(703.76 \mathrm{~g} / \mathrm{L})$ of all the experiments and a reactor productivity of $28.12 \mathrm{~g} \mathrm{FAME} \mathrm{L}^{-1}$ $\mathrm{h}^{-1}$. For Opt.1 and Opt.2 the increase in the FAME yield compared to Exp.7 was $4.14 \%$ and $3.94 \%$ respectively. What this means, from a production perspective, is that using Opt.1's feeding strategy, the reaction could be stopped 6.25 hours earlier and still have the same FAME yield as in Exp. 7. This equates to an increase in the reactor productivity of $36.9 \%$.

The increase in reactor productivity due to the optimal feeding of methanol can be can be explained by the plots shown in Fig. 5. For feeding strategies Opt.1 and Opt.2 the concentration of methanol in the reactor is below or at the optimal value of $0.525 \mathrm{Eq}$. which gave the fastest initial rate.

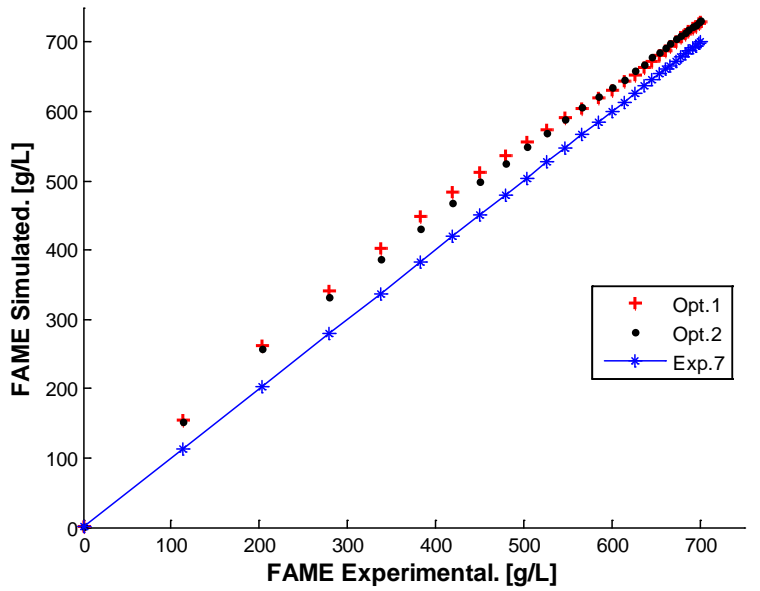

Fig. 4 Parity plot of the Exp.7 vs. the two feeding strategies. Fach point represents 50 minute increments. 

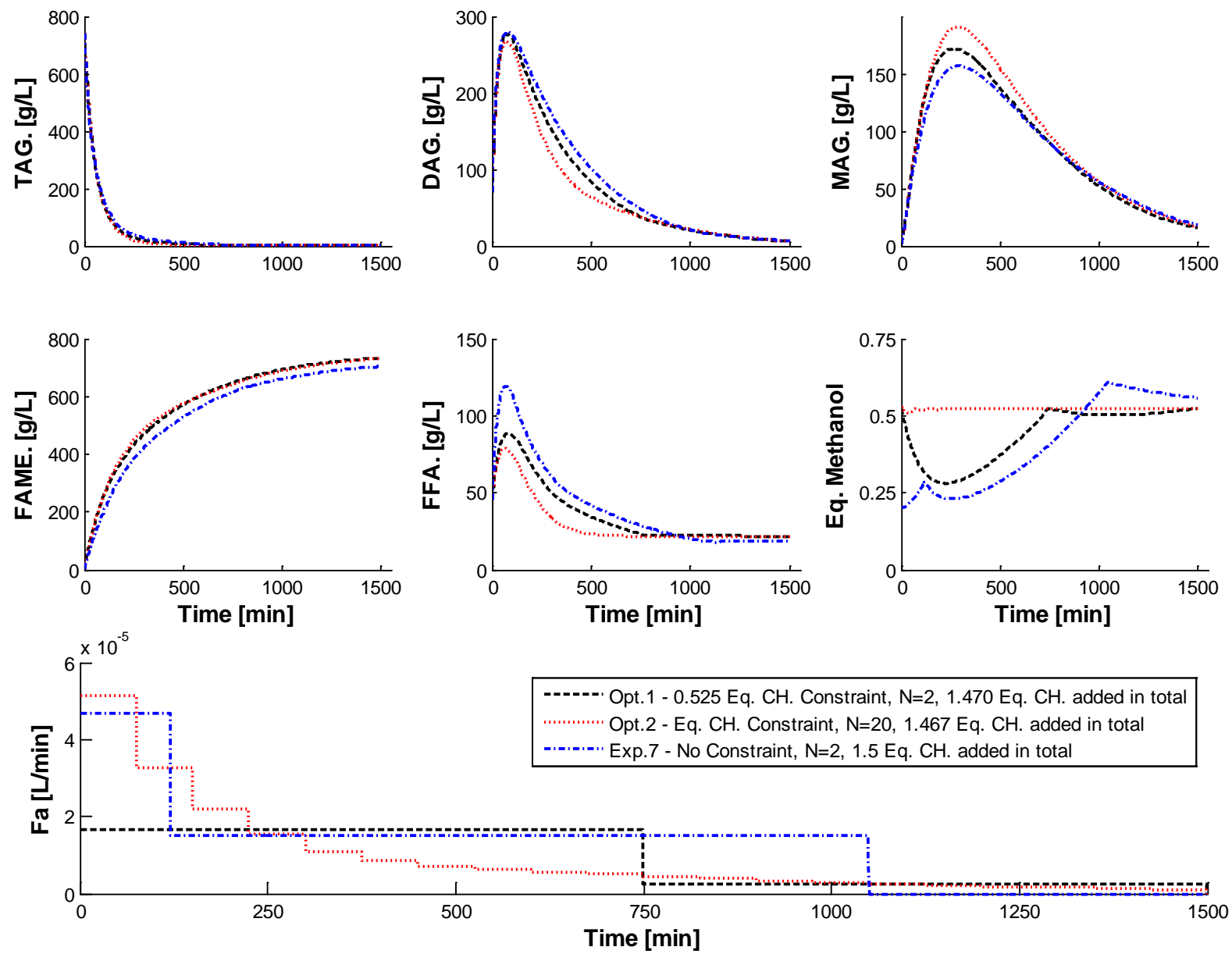

Fig. 5 Simulation of the feeding strategies for Opt.1 and Opt. 2 along with the simulation results of Exp.7 for comparis on

It is known that initial reaction rate increases with increasing methanol content, reaches a maximum, and thereafter decreases when the methanol content is further increased (AlZuhair 2005). From the simulations (not shown) this behaviour also occurs during the reaction. Given the methanol concentration never crosses the critical value of $0.525 \mathrm{Eq}$. for the two feeding strategies; the inhibition is not as severe, as compared to Exp.7.

Opt.1 has the highest FAME yield in the end of the reaction compared to Opt.2 even though it does not operate at the critical FAME concentration for the entire reaction. This is due to the fact that Opt.1 is fed more methanol than Opt.2 but still less than Exp.7. This means the optimised feeding increased the biodiesel yield while decreasing the amount of methanol that needs to be recovered in the downstream processing. The increase in FAME production for Opt.1 and Opt.2 compared to Exp.7, in the first half of the reaction is due to the increase in methanol concentration. This means there is more methanol substrate to react, giving a faster reaction before the interface is filled with other competing enzyme substrate complexes, which ultimately slows down the reaction in the later half.

Another interesting observation is that Opt.1's (also Exp.7) methanol profile for the first 700 minutes stays below 0.525 Eq. This means the enzymes in Opt.1, is not exposed to as harsh conditions as the enzymes in Opt.2 during the first half of the reaction and may provide a better environment for the enzyme, thereby decreasing the amount of enzyme that is irreversibly deactivated. However this conclusion needs to be validated in the lab by repeated reuse of the enzyme.

In Fig. 6 we use the Monte-Carlo simulations to investigate
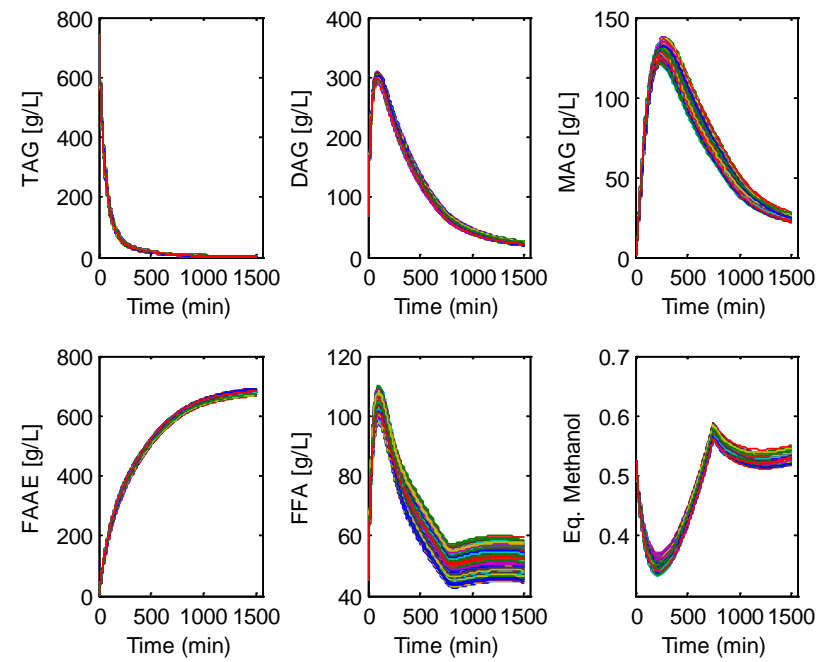

Fig. 6500 Monte-Carlo simulations for Opt.1 simulation depicting the uncertainty in the model predictions 
for Opt.1, how reliable the model is given the uncertainty in the parameter estimates. The uncertainty in the model outputs is represented using the results of the Monte-Carlo simulations, obtained from the dynamic simulation of the 500 Latin hypercube samples. The interpretation of the results is straightforward; the higher deviation of the 500 simulations, the worse the model prediction quality is. Overall the parameter uncertainty can be considered negligible on the model outputs even though the FFA model output shows some deviation. To understand which parameters are significantly influencing the uncertainty in a particular model output (such as FFA of MAG) a sensitivity analysis would need to be done, however this is beyond the scope of this paper.

\section{CONCLUSIONS}

The developed mechanistic kinetic model combined with the reactor mass balance enabled the evaluation of various feeding strategies to improve biodiesel production. Increasing the number of feed increments won't necessarily give a better yield but is dependent on the total amount of methanol that is feed to the reactor. It is important that the methanol concentration in the reactor is very close to the critical value to maximize the reactor productivity. In the end the two step feed feeding strategy, Opt.1 gave an increase in biodiesel yield off $4.14 \%$, lowered the amount of methanol that needs to be recovered and since the enzymes experiences much lower methanol concentrations this strategy may very well serve to mitigate methanol deactivation.

\section{ACKNOWLEDGMENTS}

The authors will like to acknowledge the work of Vanessa Lampreia Silva and Björn Hofmann who's experimental and analytical work made this study possible. Also this work was partly supported by the Danish National Advanced Technology Foundation (DNATF) whose support is gratefully acknowledged.

\section{REFERENCES}

Akoh, C. C., Chang, S.-W., Lee, G.-C. and Shaw, J.-F. (2007) 'Enzymatic Approach to Biodiesel Production', Journal of Agricultural and Food Chemistry, 55(22), 8995-9005.

Al-Zuhair, S. (2005) 'Production of Biodiesel by LipaseCatalyzed Transesterification of Vegetable Oils: A Kinetics Study', Biotechnology Progress, 21(5), 14421448.

Al-Zuhair, S., Ling, F. W. and Jun, L. S. (2007) 'Proposed kinetic mechanism of the production of biodiesel from palm oil using lipase', Process Biochemistry, 42(6), 951960.

Calabrò, V., Ricca, E., Paola, M. d., Curcio, S. and Iorio, G. (2010) 'Kinetics of enzymatic trans-esterification of glycerides for biodiesel production', Bioprocess and Biosystems Engineering, 33(6), 701-710.

Cheirsilp, B., H-Kittikun, A. and Limkatanyu, S. (2008) 'Impact of transesterification mechanisms on the kinetic modeling of biodiesel production by immobilized lipase', Biochemical engineering journal, 42(3), 261-269.
Du, W., Xu, Y.-Y., Liu, D.-H. and Li, Z.-B. (2005) 'Study on acyl migration in immobilized lipozyme TL-catalyzed transesterification of soybean oil for biodiesel production', Journal of Molecular Catalysis B: Enzymatic, 37(1-6), 68-71.

Fedosov, S. N., Brask, J., Pedersen, A. K., Nordblad, M., Woodley, J. M. and Xu, X. (2012) 'Kinetic model of biodiesel production using immobilized lipase Candida antarctica lipase B', Journal of Molecular Catalysis B: Enzymatic, 85-86, 156-168.

Helton, J. C. and Davis, F. J. (2003) 'Latin hypercube sampling and the propagation of uncertainty in analyses of complex systems', Reliability Engineering \& System Safety, 81(1), 23-69.

Jeffrey C. Lagarias, J. A. R., Margaret H. Wright, Paul E. Wright (1998) Convergence Properties of the NelderMead Simplex Method in Low Dimensions.

Jurado, E., Camacho, F., Luzón, G., Fernández-Serrano, M. and García-Román, M. (2008) 'Kinetics of the enzymatic hydrolysis of triglycerides in $\mathrm{o} / \mathrm{w}$ emulsions: Study of the initial rates and the reaction time course', Biochemical Engineering Journal, 40(3), 473-484.

Li, W., Li, R.-W., Li, Q., Du, W. and Liu, D. (2010) 'Acyl migration and kinetics study of 1(3)-positional specific lipase of Rhizopus oryzae-catalyzed methanolysis of triglyceride for biodiesel production', Process Biochemistry, 45(12), 1888-1893.

Lv, D., Du, W., Zhang, G. and Liu, D. (2010) 'Mechanism study on NS81006-mediated methanolysis of triglyceride in oil/water biphasic system for biodiesel production', Process Biochemistry, 45(4), 446-450.

Nielsen, P. M., Brask, J. and Fjerbaek, L. (2008) 'Enzymatic biodiesel production: Technical and economical considerations', European Journal of Lipid Science and Technology, 110(8), 692-700.

Pilarek, M. and Szewczyk, K. W. (2007) 'Kinetic model of 1,3-specific triacylglycerols alcoholysis catalyzed by lipases', Journal of Biotechnology, 127(4), 736-744.

Price, J., Nordblad, M., Woodley, J. M. and Huusom, J. K. (2013) 'Application of Uncertainty and Sensitivity Analysis to a Kinetic Model for Enzymatic Biodiesel Production', in Preprint 12th IFAC Symposium on Computer Applications in Biotechnology,

Samukawa, T., Kaieda, M., Matsumoto, T., Ban, K., Kondo, A., Shimada, Y., Noda, H. and Fukuda, H. (2000) 'Pretreatment of immobilized Candida antarctica lipase for biodiesel fuel production from plant oil', Journal of Bioscience and Bioengineering, 90(2), 180-183.

Sin, G., Gernaey, K. V. and Lantz, A. E. (2009) 'Good modeling practice for PAT applications: Propagation of input uncertainty and sensitivity analysis', Biotechnology Progress, 25(4), 1043-1053.

Xu, Y., Nordblad, M., Nielsen, P. M., Brask, J. and Woodley, J. M. (2011) 'In situ visualization and effect of glycerol in lipase-catalyzed ethanolysis of rapeseed oil', Journal of Molecular Catalysis B: Enzymatic, 72(3-4), 213-219. 